\title{
ANATOMIA DA MADEIRA DE ACACIA PODALYRIAEFOLIA A. CUNN. ${ }^{1}$
}

\author{
JOSÉ NEWTON CARDOSO MARCHIORI²
}

\section{RESUMO}

São anatomicamente descritos os caracteres gerais, macroscópicos e microscópicos da madeira de Acacia podalyriaefolia A. Cunn. A presença de fibras libriformes não septadas e de raios estreitos, uni a trisseriados, são reconhecidas como de valor diagnóstico para o subgênero Heterophyllum Vassal.

Palavras-chave: Acacia podalyriaefolia, subgênero Heterophyllum Vassal, anatomia da madeira.

\section{SUMMARY}

[Wood anatomy of Acacia podalyriaefolia A. Cunn.].

The general, macroscopic and microscopic wood features of Acacia podalyriaefolia A. Cunn. are described. The fine rays (1 - 3-seriate) and the libriform non-septate fibers are recognized as typical to subgenus Heterophyllum Vassal.

Key words: Acacia podalyriaefolia, subgenus Heterophyllum Vassal, wood anatomy.

\section{INTRODUÇÃO}

A literatura anatômica sobre o gênero Acacia (Tourn.) Miller é reconhecidamente escassa, face à importância econômica e diversidade de espécies nativas e cultivadas no continente americano. Em Timbers of the New World, por exemplo, Record \& Hess (1949) não fazem qualquer referência ao mesmo, apesar do numeroso contingente neotropical.

Em estudo de madeiras argentinas, Cozzo (1951) não observou diferenças anatômicas importantes entre as 13 espécies de Acacia, por ele investigadas, motivo pelo qual refere-se ao gênero como estruturalmente homogêneo. $\mathrm{O}$ autor fornece diagnoses anatômicas para as distintas espécies e uma chave dicotômica para a identificação das mesmas.

1 Recebido em 23-6-2009 e aceito para publicação em 30-11-2009.

2 Engenheiro Florestal, Dr., bolsista de Produtividade em Pesquisa (CNPq - Brasil), Professor Titular do Departamento de Ciências Florestais, Universidade Federal de Santa Maria, Santa Maria, RS, Brasil.
Diferentemente do autor argentino, Marchiori (1980) observou semelhança estrutural entre Acacia tucumanensis Gris e Acacia bonariensis Gill. ex Hook. \& Arn., da série Vulgares Benth., e diferenças importantes entre estas e Acacia caven (Mol.) Mol., pertencente à série Gummiferae Benth. Para a distinção dos referidos grupos infragenéricos, o autor valeuse da presença ou não de septos em fibras, do arranjo do parênquima axial e da morfologia dos raios.

Em estudo de 37 espécies sul-africanas, Robbertse et al. (1980) valeram-se da dimensão dos raios para a distinção de subgêneros e, com menor importância, da presença de anéis de crescimento, da frequiência de poros e da distribuição do parênquima axial. Todas as 14 espécies estudadas do subgênero Aculeiferum Vassal apresentaram raios estreitos (2-5-seriados), em contraste com as 23 espécies investigadas do subgênero Acacia Vassal, reconhecidas pelos raios mais largos, com 4 a 14 células de largura.

Nativa da Austrália, Acacia podalyriaefolia A. Cunn. é popularmente conhecida, em seu país 
de origem, como "Queensland silver wattle" (National Academy of Sciences, 1979); no Brasil, a espécie recebe os nomes comuns de "mimosa" ou "acacia-mimosa" (Schultz, 1975). Trata-se de arbusto ou arvoreta bastante valorizada, no paisagismo, pelo efeito ornamental de sua folhagem acinzentada e vistosa floração de inverno. Sob o ponto de vista taxonômico, a espécie inclui-se na série Phyllodineae e subsérie Uninerves (Bentham, 1875) ou, então, no subgênero Heterophyllum (Vassal, 1972).

Das numerosas espécies do subgênero Heterophyllum Vassal, introduzidas como ornamentais ou madeireiras no Rio Grande do Sul, apenas Acacia mearnsii De Willd. (Costa \& Marchiori, 1980), Acacia longifolia (Andr.) Willd. (Illana \& Marchiori, 1980) e Acacia melanoxylon R. Br. (Marchiori, 2009) dispõem de descrições detalhadas da estrutura microscópica da madeira. Sob o ponto de vista anatômico, estas três espécies exóticas distinguem-se das nativas por terem fibras não septadas e parênquima axial pouco abundante (20\%, no máximo), com 2 a 4 células por série. Resta salientar que no subgênero Aculeiferum Vassal as espécies apresentam fibras septadas, distintamente do subgênero Acacia Vassal, reconhecido pelo parênquima mais conspícuo e abundante, com 2 células (raro mais) por série.

\section{MATERIAL E MÉTODOS}

O material estudado consiste de três amostras de madeira e respectivo material botânico, conservados na Xiloteca e Fitoteca do Departamento de Ciências Florestais da Universidade Federal de Santa Maria (HDCF) com os seguintes registros:

- Longhi, S.J., n. 77 (5-7-1977); Campus da UFSM, Santa Maria, RS. Flores; exemplar cultivado. HDCF 306.

- Marchiori, J.N.C., s/n (15-10-1978). Curitiba, PR.

- Marchiori, J.N.C., n. 914 (15-10-1988); Pedras Altas, Pinheiro Machado, RS. HDCF 3314; UFPR 1371.
De cada amostra foram preparados três corpos-de-prova, orientados para a obtenção de cortes anatômicos nos planos transversal, longitudinal radial e longitudinal tangencial, respectivamente. A microtomia seguiu a técnica padrão no Laboratório de Anatomia da Madeira da Universidade Federal do Paraná: os corpos de prova foram amolecidos por fervura em água e seccionados em micrótomo de deslizamento, regulado para a obtenção de cortes anatômicos com espessura nominal de $18 \mu \mathrm{m}$. Os cortes foram coloridos com acridina-vermelha, crisoidina e azul-de-astra (Dujardin, 1964), desidratados em série alcoólica $(25 \%, 50 \%$, $75 \%, 90 \%, 95 \%$, duas vezes álcool absoluto), diafanizados em xilol e montados em lâminas permanentes com "Entellan". Na confecção de lâminas de macerado, usou-se a técnica de Jeffrey (Freund, 1970), coloração com safranina e o mesmo meio de montagem.

A terminologia, número de medições e descrição da estrutura anatômica seguiram as recomendações da Copant (1973), com as modificações introduzidas por Burger (1979). As determinações estereológicas da percentagem de vasos, parênquima axial, raios e fibras, bem como da percentagem das classes de raios quanto à largura em número de células, seguiram a metodologia recomendada por Marchiori (1980). A cor da madeira foi determinada por comparação com a "Tabela de Cores para Solos" (Munsell, 1971), sob iluminação natural. As fotomicrografias foram tomadas em aparelho Carl Zeiss.

\section{DESCRIÇÃO DA MADEIRA}

Caracteres gerais:

Cerne e alburno distintos; alburno estreito, amarelo-palha (HUE 2.5 YR 8/4), com zonas castanho-claras (HUE 10 YR 7/3) e cerne rosado (HUE 7.5 YR 7/4). Madeira de grã direita, brilho acentuado, macia, de textura fina, não aromática, com figura produzida pela variação de cor e brilho. 

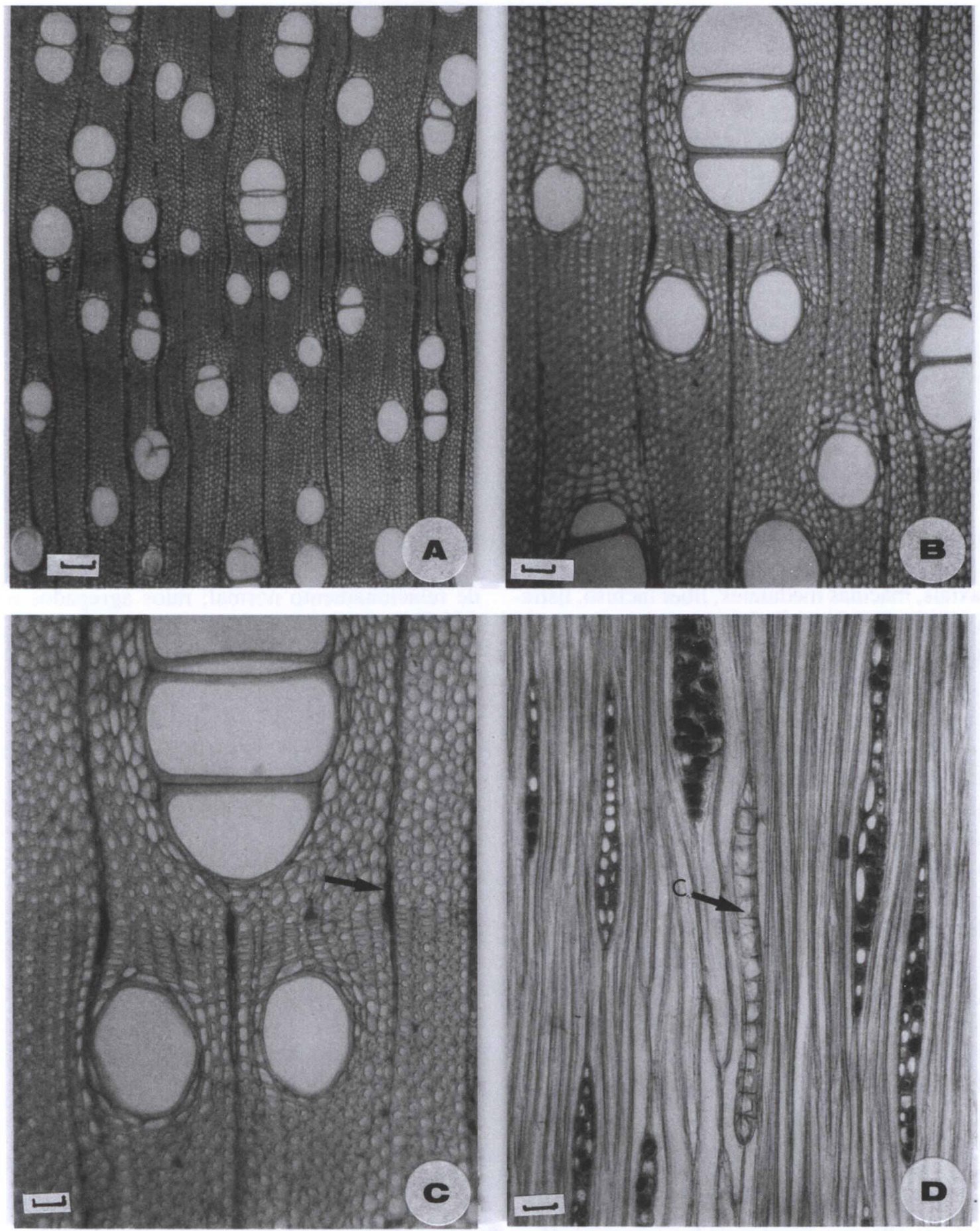

FIGURA 1 - Aspectos anatômicos da madeira de Acacia podalyriaefolia. A - Limite de anel de crescimento e porosidade difusa, com poros solitários ou em múltiplos radiais (seção transversal). B - Limite de anel de crescimento, em maior aumento, marcado por fibras radialmente estreitas (seção transversal). C - O mesmo campo, em detalhe, destacando o limite de anel de crescimento e a abundância de goma em células radiais (seta). D - Raios lenhosos e série cristalífera (seta), em seção longitudinal tangencial. Escalas = $100 \mu \mathrm{m}$ (A); $40 \mu \mathrm{m}$ (B); $25 \mu \mathrm{m}$ (C, D). 


\section{Caracteres macroscópicos:}

Parênquima axial: visível apenas com lente de 10 aumentos; escasso, em arranjo paratraqueal vasicêntrico.

Raios: invisíveis a olho nu em plano transversal, finos, pouco freqüentes; visíveis com dificuldade sob lente em plano longitudinal tangencial, baixos, não estratificados. Espelhado, pouco contrastado.

Poros: invisíveis a olho nu, pequenos, muito numerosos e em distribuição difusa, não uniforme. Poros solitários e em pequenos múltiplos de 2 a 4, agrupados radialmente ou em cachos. Linhas vasculares retilíneas, freqüentemente obstruídas por conteúdo vermelho-escuro, com aspecto de goma, sobretudo no cerne.

Camadas de crescimento: distintas, marcadas por zonas fibrosas tangenciais mais escuras.

Outros caracteres: canais secretores axiais, máculas medulares, líber incluso, listrado de estratificação e canais secretores horizontais, ausentes.

\section{Caracteres microscópicos:}

Vasos: ocupando $16 \%$ da seção transversal da madeira, muito numerosos $(10-22-39$ / $\mu \mathrm{m} ; \mathrm{s}=8,36$ ), de forma oval, com $40-96-135$ $\mu \mathrm{m}$ de diâmetro $(\mathrm{s}=23,54)$, paredes espessas $(1,3-3,6-5 \mu \mathrm{m} ; \mathrm{s}=1,01)$ e distribuição difusa, não uniforme, ligeiramente mais abundantes nos limites de anéis de crescimento. Poros solitários e em múltiplos de 2 a 6 , dispostos em agrupamentos radiais, menos freqüentemente em cachos (Figura 1A). Elementos vasculares curtos $(180-310-440 \mu \mathrm{m} ; \mathrm{s}=66,34)$. Placas de perfuração simples, transversais ou ligeiramente oblíquas aos vasos. Apêndices geralmente curtos $(20-59-120 \mu \mathrm{m} ; \mathrm{s}=25,25)$, em uma ou em ambas as extremidades. Espessamentos espiralados, ausentes. Pontoações intervasculares alternas, ornamentadas, pequenas ( 6 $7-8 \mu \mathrm{m} ; \mathrm{s}=0,63$ ) e de forma oval (Figura 2C), com abertura lenticular, inclusa ou coalescente a várias pontoações. Pontoações raio-vasculares (Figura 2B) e parênquimo-vasculares (Figura
2D) pequenas, arredondadas e em arranjo alterno. Conteúdo com aspecto de goma, abundante em vasos do cerne.

Parênquima axial: ocupando cerca de 13\% do volume da madeira; em arranjo paratraqueal escasso até vasicêntrico e aliforme (Figura 2C). Células fusiformes de $192-306-440 \mu \mathrm{m}$ de altura $(\mathrm{s}=68,99)$ e $12-19-35 \mu \mathrm{m}$ de largura $(s=4,95)$. Séries verticais não estratificadas, de $225-320-407 \mu \mathrm{m}$ de altura $(\mathrm{s}=37,80)$ e 9 $-19-40 \mu \mathrm{m}$ de largura $(\mathrm{s}=7,89)$, compostas de 2 a 4 células (Figura 2C, D). Cristais romboédricos de oxalato de cálcio com cerca de $25 \mu \mathrm{m}$ de comprimento, em séries de 12 a 17 câmaras, na periferia do parênquima paratraqueal.

Raios: homogêneos (Figura 2A, B), ocupando cerca de $8 \%$ do volume da madeira. Raios pouco numerosos $(4-6,6-10 / \mathrm{mm} ; \mathrm{s}=1,48) \mathrm{e}$ de relacionamento normal; raios agregados e fusionados, ausentes (Figuras 1D, 2C). Raios unisseriados, abundantes ( $25 \%$ do total); muito baixos $(15-102-240 \mu \mathrm{m}$; $\mathrm{s}=42,11)$, extremamente finos $(6-13-16 \mu \mathrm{m} ; \mathrm{s}=2,40)$ e com 1- 6 - 17 células de altura. Os multisseriados, em sua maioria com 2 células de largura (60\% do total), menos freqüentemente trisseriados (15\%); baixos $(112-239-500 \mu \mathrm{m}$; $=109,08)$, com $6-15-34$ células de altura $(s=7,63)$, e muito finos $(12-21-43 \mu \mathrm{m} ; \mathrm{s}=5,02)$. Células cristalíferas, envolventes, eretas, esclerosadas, latericuliformes, oleíferas e quadradas, ausentes. Goma, abundante em células radiais (Figura $1 \mathrm{C})$.

Fibras: abundantes, ocupando $63 \%$ do volume da madeira; são libriformes, não septadas, muito curtas $(730-875-1050 \mu \mathrm{m} ; \mathrm{s}=84,78)$, estreitas $(9-13-24 \mu \mathrm{m} ; \mathrm{s}=2,81)$ e de paredes delgadas $(1,8-3,5-5 \mu \mathrm{m} ; \mathrm{s}=0,92)$. Pontoações simples, diminutas, presentes tanto nas faces radiais como tangenciais da parede; fibras gelatinosas, não observadas. Espessamentos espiralados, ausentes.

Outros caracteres: Canais secretores, tubos laticíferos e taniníferos, líber incluso, máculas 

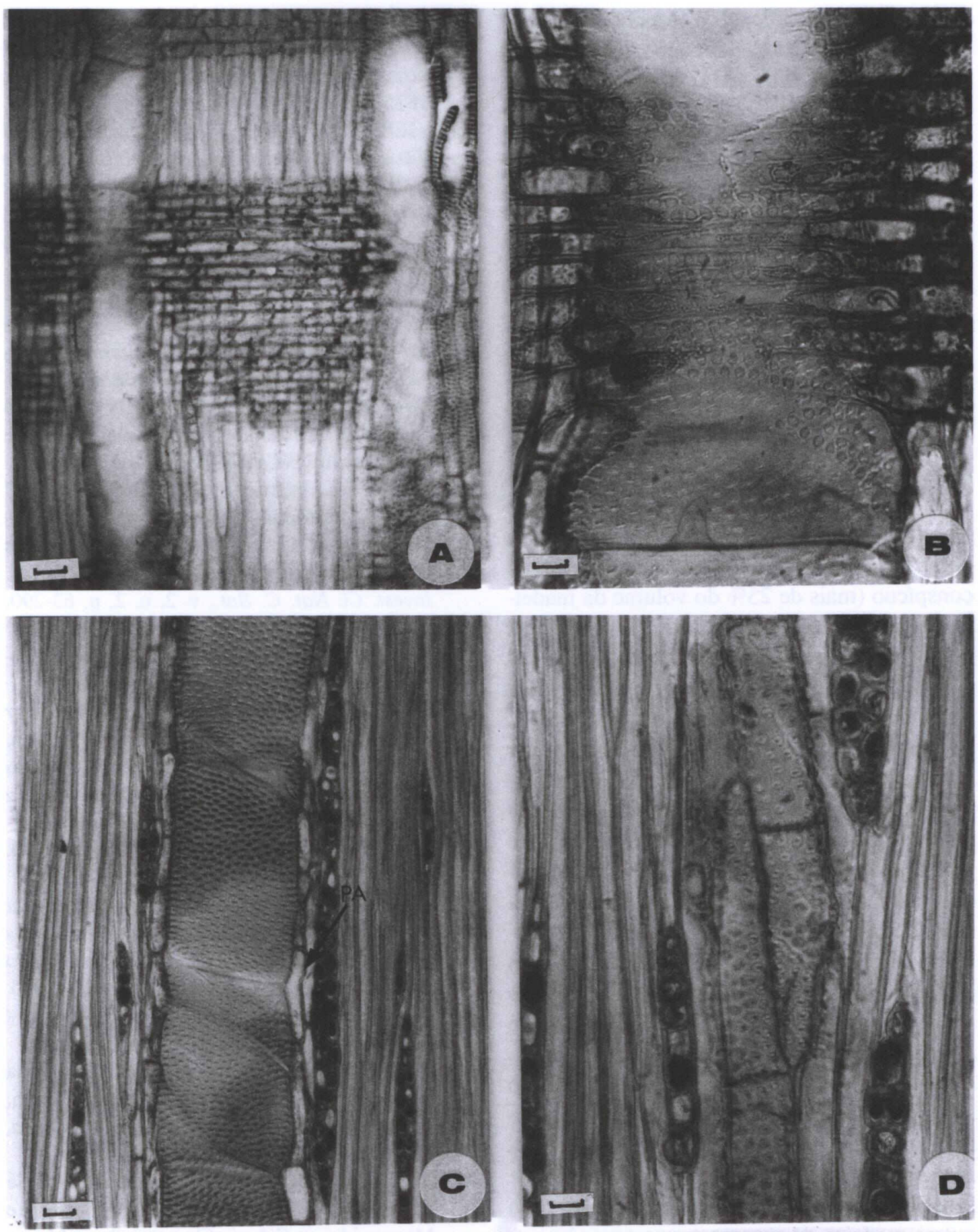

FIGURA 2 - Detalhes anatômicos da madeira de Acacia podalyriaefolia. A-Raios homogêneos, compostos inteiramente de células horizontais (seção longitudinal radial). B - Pontoações raio-vasculares pequenas e arredondadas, em arranjo alterno (seção longitudinal radial). C - Raios uni e multisseriados, parênquima paratraqueal (PA) e vaso com pontoações intervasculares alternas (seção longitudinal tangencial). D - Detalhe de pontoações parênquimo-vasculares, em seção longitudinal tangencial. Escalas $=40 \mu \mathrm{m}(\mathrm{A}) ; 25 \mu \mathrm{m}(\mathrm{C}) ; 12,5 \mu \mathrm{m}(\mathrm{B}, \mathrm{D})$. 
medulares e estratificação, ausentes. Anéis de crescimento distintos, marcados por fibras radialmente estreitas no lenho tardio (Figura 2A, B, C).

\section{ANÁLISE DA ESTRUTURA ANATÔMICA}

A estrutura anatômica descrita difere, em aspectos importantes, do referido na literatura para oito espécies nativas no Rio Grande do Sul: Acacia caven (Marchiori, 1980, 1992), Acacia ibirocayensis (1993), Acacia bonariensis (Marchiori, 1980, 1996), Acacia nitidifolia (Marchiori, 1991a), Acacia plumosa (Marchiori, 1991b), Acacia recurva (Marchiori, 1982), Acacia tucumanensis (Marchiori, 1980, 1994) e Acacia velutina (Marchiori, 1995). Destas, as duas primeiras, que pertencem ao subgênero Acacia Vassal, distinguem-se de Acacia podalyriaefolia por terem parênquima axial conspícuo (mais de $25 \%$ do volume da madeira), com duas células por série (raro 3), bem como pelos abundantes raios com mais de 4 células de largura. Das outras seis espécies, integrantes do subgênero Aculeiferum Vassal, A. podalyriaefolia separa-se, prontamente, por ter fibras não septadas.

A ausência de septos em fibras, aliada a parênquima relativamente escasso (cerca de $13 \%$ ), aspectos constantes na presente descrição anatômica, foram também registrados para as madeiras de Acacia mearnsii De Willd (Costa \& Marchiori, 1980), Acacia longifolia (Andr.) Willd. (Illana \& Marchiori, 1980) e Acacia melanoxylon R. Br. (Marchiori, 2009). Cabe assinalar que estas três espécies, assim como Acacia podalyriaefolia, pertencem ao mesmo subgênero, motivo pelo qual os referidos aspectos anatômicos podem ter valor diagnóstico para Heterophyllum Vassal. Recomenda-se, neste sentido, o desenvolvimento de pesquisas com outras espécies do mesmo grupo taxonômico, com vistas a confirmar a hipótese aventada.

\section{REFERÊNCIAS BIBLIOGRÁFICAS}

BENTHAM, G. Revision of the sub-order Mimoseae. Trans. Linn. Soc. London, n. 30, p. 335-664, 1875.

BURGER, L.M. Estudo anatômico do xilema secundário de sete espécies nativas do gênero Dalbergia, Leguminosae-Faboideae. Curitiba: UFPR, 1979. 184 f. Dissertação (Mestrado em Engenharia Florestal) - Universidade Federal do Paraná.

COPANT. Comissão Panamericana de Normas Técnicas. Descrição macroscópica, microscópica e geral da madeira - Esquema I de recomendação. Colômbia, 1973. 19 p. (COPANT 30).

COSTA, A.F. da; MARCHIORI, J.N.C. Estudo anatômico da madeira de Acacia mearnsii De Willd. In: Anais do IV Congresso Florestal Estadual. Nova Prata, RS, 1980. p. 237-245.

COZZO, D. Anatomia del leño secundario de las Leguminosas Mimosoideas y Caesalpinoideas argentinas silvestres y cultivadas. Rev. Inst. Nac. Invest. Ci. Nat. C. Bot., v. 2, n. 2, p. 63-290, 1951.

DUJARDIN, E.P. Eine neue Holz-Zellulosenfaerbung. Mikrokosmos, n. 53, p. 94, 1964.

FREUND, H. Handbuch der Mikroskopie in der Technik. Frankfurt: Umsham Verlag, 1979.379p.

ILLANA, H.A.; MARCHIORI, J.N.C. Estudo anatômico do xilema secundário de Acacia longifolia (Andr.) Willd. In: Anais do IV Congresso Florestal Estadual. Nova Prata, RS, 1980. p. 207-215.

MARCHIORI, J.N.C. Estudo anatômico do xilema secundário e da casca de algumas espécies dos gêneros Acacia e Mimosa, nativas no Estado do Rio Grande do Sul. Curitiba, UFPR, 1980. 186 f. Dissertação (Mestrado em Engenharia Florestal) - Universidade Federal do Paraná.

MARCHIORI, J.N.C. Estudo anatômico do xilema secundário e da casca de Acacia recurva Benth. (Leguminosae Mimosoideae). Ciência e Natura, Santa Maria, v. 4, p. 95-105, 1982.

MARCHIORI, J.N.C. Anatomia da madeira de Acacia nitidifolia Speg. (Leguminosae Mimosoideae). Ciência Florestal, Santa Maria, v.1, n. 1, p. 46-63, 1991a. 
MARCHIORI, J.N.C. Anatomia da madeira de Acacia plumosa Lowe (Leguminosae Mimosoideae). Ciência e Natura, Santa Maria, v. 13, p. 67-77, 1991b.

MARCHIORI, J.N.C. Anatomia da madeira e casca do espinilho, Acacia caven (Mol.) Mol. Ciência Florestal, Santa Maria, v. 2, n. 1, p. 27-47, 1992.

MARCHIORI, J.N.C. Estudo anatômico do xilema secundário de Acacia ibirocayensis Marchiori (Leguminosae Mimosoideae). Ciência e Natura, Santa Maria, v. 15, p. 149-159, 1993.

MARCHIORI, J.N.C. Anatomia da madeira e casca de Acacia tucumanensis Gris. Ciência \& Natura, Santa Maria, n. 16, p. 85-104, 1994.

MARCHIORI, J.N.C. Anatomia da madeira e casca de Acacia velutina DC. Ciência e Natura, Santa Maria, n. 17, p. 99-114, 1995.

MARCHIORI, J.N.C. Anatomia da Madeira de Acacia bonariensis Gill. ex Hook. et Arn. Ciência Rural, Santa Maria, v. 26, n. 2, p. 209-216, 1996.
MARCHIORI, J.N.C. Anatomia da madeira de Acacia melanoxylon R. Br. Balduinia, Santa Maria, n. 18, p. 26-32, 2009.

MUNSELL COLOR DIVISION. Soil Color Charts. Baltimore, 1971. s.p.

NATIONAL ACADEMY OF SCIENCES. Tropical legumes - Resources for the future. Washington: National Academy Press, 1979. 326 p.

RECORD, S.J.; HESS, R.W. Timbers of the New World. New Haven: Yale University Press, 1949. 640 p.

ROBBERTSE, P.J.; VENTER, G.; RENSBURG, H.J. van. The wood anatomy of the South African Acacias. IAWA Bulletin, v. 1, n. 3, p. 93-103, 1980.

SCHULTZ, A.R. Os nomes científicos e populares das plantas do Rio Grande do Sul. Porto Alegre: PUC/EMMA, 1975. 164 p.

VASSAL, J. Ontogenetic and seed research applied to the morphological, taxonomical and phylogenetic study of the genus Acacia. Travaux Lab. For. Toulouse, v.1, n. 8, art. 17, 1972. 125 p. 